Conferencia magistral

\title{
SOBRE LA LEY 19875 DE PRORROGA DE ELECCIONES DEPARTAMENTALES.*
}

\section{ABOUT LAW 19,875 ON LOCAL GOVERNMENT ELECTION POSTPONEMENT}

\section{SOBRE A LEI 19.875 DE PRORROGAÇÃO DE ELEIÇÕES DEPARTAMENTAIS}

\section{Jaime Ruben Sapolinski**}

El 8 de abril de 2020, se promulgó la Ley 19875, que prorrogó la fecha de celebración de las elecciones departamentales, cometiéndole a la Corte Electoral la fijación de la fecha, no más allá del 4 de octubre de 2020. El tenor de La ley, sobre todo antes de su sanción, permitió sostener un cúmulo de matices diversos, en buena medida consecuencia del desconcierto a que nos veíamos sometidos.

La ley, cuya redacción fue acordada por representantes de casi todos los partidos con representación parlamentaria (tenemos entendido que en las tratativas no hubo representación del Partido Ecologista Radical Independiente), consta de 4 artículos.

El artículo $1^{\circ}$ consiste, prácticamente, en una exposición de motivos, una explicación del por qué se sanciona una ley que nos resulta, a todos los que creemos en la necesidad de la aplicación de los preceptos constitucionales, un bocado difícil de digerir.

Esencialmente, declara que, en virtud de la emergencia sanitaria nacional, no están dadas las garantías para la celebración de las elecciones previstas, por mandato constitucional, para el 10 de mayo de 2020, tal como resultaba de lo dispuesto por el artículo 77 numeral $9^{\circ}$ de la Constitución de la República. El artículo hace una referencia a la salud pública, a la implementación de las medidas tendentes a su preservación y menciona el Decreto 93/2020 por el que el Poder Ejecutivo, declaró el estado de emergencia y dispuso medidas tendientes a la contención de la pandemia, como la suspensión de los espectáculos públicos, el cierre preventivo y provisorio de los centros turísticos termales públicos y privados, la cuarentena obligatoria por 14 días, de las personas que se encontraran en situación de riesgo y se arrogó la posibilidad de disponer el cierre de lugares de acceso público e imponer medidas necesarias para evitar aglomeraciones.

Se ha dicho que el artículo $1^{\circ}$ de la ley que comentamos ha pretendido conferirle jerarquía

\footnotetext{
* Conferencia magistral dictada por el autor en la jornada académica de 21 de mayo de 2020, "La Constitución en tiempos de pandemia”, organizada por el Instituto de Derecho Constitucional de la Facultad de Derecho de la Universidad de la República. Texto corregido para su publicación como conferencia por el autor.

** Doctor en Derecho y Ciencias Sociales. Profesor Titular de Derecho Constitucional en la Facultad de Derecho de la Universidad de la República. Profesor titular de Derecho Constitucional en la Universidad CLAEH. Correo electrónico: sapolins@adinet.com.uy
} 
legal al Decreto 93/2020, interpretación que no tenemos el honor de compartir. Parécenos claro que la referencia al Decreto, que pudo haberse obviado, tiene por principal propósito situar el marco en que se sanciona la ley, y que las potestades que refiere dicho Decreto no son otras que las previstas en la antigua ley de salud pública $\mathrm{N}^{0} 9202$, de 12 de enero de 1934, en particular en sus artículos $2^{\circ}, 4^{\circ}$ y $9^{\circ}$.

De todos modos, la referencia expresada puede ser vista como un espaldarazo a las medidas mencionadas en el Decreto, que contribuiría a defender su legalidad para el hipotético caso de que la misma se controvirtiera.

Sobre la falta de garantías para llevar adelante el proceso electoral en la fecha indicada, había habido un pronunciamiento oficioso de los integrantes de la Corte Electoral y resultaba, además, un hecho notorio. La ley invoca, además, con buen criterio, la necesidad de protección de los derechos fundamentales consagrados en las secciones $2^{\mathrm{a}} \mathrm{y}$ de los derechos políticos declarados en la sección $3^{\mathrm{a}}$, de la Constitución de la República. Como acotación por nuestra parte, cabe recordar que el Estado tiene por cometido esencial, proteger los derechos aludidos. Como surge del artículo $7^{\circ}$ de la Carta, los habitantes de la República tienen derecho a ser protegidos en el goce de sus derechos fundamentales y si esa protección no se alcanza con un mínimo grado de satisfacción el Estado deviene en fallido.

El artículo $2^{\circ}$ de la ley faculta a la Corte Electoral a prorrogar, por única vez la fecha de las elecciones, no más allá del 4 de octubre de 2020. Se estableció un plazo para la fijación de la fecha y se impuso adoptar la decisión por la mayoría prevista por el artículo 327 de la Constitución, previsto originalmente para la anulación de un acto electoral es decir por, al menos seis integrantes, de los que, por lo menos tres deben contarse entre los cinco miembros conocidos como "neutrales" (designados por dos tercios de integrantes de la Asamblea General). Como es notorio, la fecha fijada por la Corte Electoral, fue el 27 de setiembre.

Finalmente, el artículo dispone que el padrón electoral a emplearse será el que se iría a utilizar en las elecciones que se postergan lo que se justifica por las dificultades que podría tener un armado de emergencia del padrón electoral y porque se trata de remedar la elección no cumplida. Yo diría que es un remedo y un remiendo, pero, posiblemente inevitable.

El artículo comentado hace referencia al artículo 322 literal A de la Constitución que le atribuye a la Corte Electoral la competencia para conocer de todo lo relacionado con los actos y procedimientos electorales.

Precisamente, esa competencia atribuida, ha permitido sostener que la suspensión podía haber sido establecida, simplemente, por resolución de la Corte Electoral, que esta disposición de la ley es superflua y hasta que invade las competencias de la Corte, posición que tiene un sustento razonable. Cabría sostener que una decisión de la Corte que hubiera 
reconocido los hechos en su cruda realidad no habría dejado de ser un acto lícito. Claro que, si afinamos el punto de mira, el mencionado literal A del artículo 322, a pesar de su amplitud, no dice que la Corte Electoral pueda cambiar la fecha de las elecciones pautada en la Constitución, no al menos en condiciones normales.

Podría considerarse que la consagración de la prórroga por parte del legislador, confiriéndole a la Corte la posibilidad de fijarla dentro de determinados límites, aunque innecesaria, no es estéril; porque la ley, máxime teniendo en cuenta el apoyo obtenido en su sanción, demuestra el consenso general alcanzado por los diversos representantes de la nación, en el ámbito legislativo y en sus diversas manifestaciones. Recordemos, fue votada por unanimidad en la Cámara de Senadores y por 92 votos en 93 en la Cámara de Representantes.

La exigencia del quórum previsto por el artículo 327 para la anulación de las elecciones, apunta a mi juicio a demostrar, también, el amplio consenso existente en torno a una situación que se advirtió como irresistible, esta vez en el ámbito de la propia Corte Electoral. Señalemos que, aunque pueda haber alguna analogía entre esta situación y la de anulación de las elecciones, es muy remota. Este caso no es una situación de anulación de elecciones que, obviamente, consiste en una situación crítica en la que la Corte, en ejercicio de sus competencias jurisdiccionales, declara la nulidad de un acto electoral por circunstancias invalidantes como podría ser una situación de violencia o fraude.

La referencia legal no abarca, no tendría sentido que lo hiciera, la obligación de celebrar por segunda vez, en forma parcial si fuera posible, la elección anulada total o parcialmente, el segundo domingo posterior a la fecha de pronunciamiento de la nulidad.

El artículo $3^{\circ}$ dispone que los Intendentes, miembros de las Juntas Departamentales y de los Municipios continuarán en el desempeño, hasta la asunción de las nuevas autoridades electas, lo que condice con lo dispuesto por el artículo 268, inciso final de la Constitución, en cuanto dispone: "Si en la fecha en que deba asumir sus funciones no estuviese proclamado el Intendente electo o fuese anulada la elección departamental quedará prorrogado el período del Intendente cesante, hasta que se efectúe la transmisión del mando".

El artículo $4^{\circ}$, de la ley, de modo concordante, y en la procura de mantener en la medida de lo posible, los mecanismos institucionales, dispone que los electos iniciarán su gestión, de acuerdo con lo dispuesto por el artículo 262 de la Constitución, es decir el 15 de febrero siguiente a la elección y cesarán "cuando asuman las autoridades electas en el próximo período electoral de conformidad con lo establecido en el Artículo 77 numeral $9^{\circ}$, , o sea el segundo domingo del mes de mayo del año siguiente al de las próximas elecciones nacionales. Es, si se quiere, el criterio seguido por el constituyente para el caso de elecciones parlamentarias, en mitad de un período de gobierno, en el remoto caso de que se produjera la disolución de las Cámaras, luego de la censura ministerial, de acuerdo 
con el artículo 148, inciso final que dice: "Las Cámaras elegidas extraordinariamente, completarán el término de duración normal de las cesantes".

Lo peculiar de la situación presente, determinó que se vertieran diversas opiniones, sobre las virtudes del medio utilizado, o sea de la ley que estamos refiriendo y sobre la adecuación para brindarle solución al problema que se estaba planteando y partiendo de la convicción generalizada de la imposibilidad de la realización de elecciones. Ha habido una gama de opiniones, algunas vertidas en la prensa, otras en encuentro telemáticos, de muy destacados colegas que aportaron perspectivas plausibles, aunque diversas que intentaré resumir:

Se sostuvo que:

a. El sistema constitucional es una unidad inescindible y que cabría la posibilidad de una ley interpretativa, en el marco del artículo 85 numeral $20^{\circ}$ de la Carta, que reconociera la primacía del derecho a la salud. (Posición del Dr. Martín Risso)

b. Que la forma de salvar la inconstitucionalidad sería la aprobación de una reforma constitucional, sustanciada mediante el procedimiento del artículo 331 literal D de la Constitución, denominado de las leyes constitucionales, a plebiscitarse en la misma oportunidad de la elección. (Posición a la que adhirieron los Dres. Correa Freitas, Esteva y el Catedrático de Sistemas Electorales, Prof. Bottinelli. También fue la posición del Representante Nacional, Dr. Pasquet)

c. Que se trata de una situación de conmoción interior que justificaría la aplicación de las medidas prontas de seguridad previstas en el artículo 168 numeral 17 de la Constitución. (Posición que manejó el Dr. Gutiérrez, en un artículo publicado en la prensa salteña)

d. Que correspondía a la Corte Electoral resolver el punto, en virtud de que dispone de competencia bastante a ese respecto (Sostenido por el Dr. Sarlo en un encuentro telemático organizado por la Revista de Derecho Público)

e. En cuanto a las opiniones que también se vertieron sobre dejar de considerar obligatoria la elección, por una única vez corresponde mencionar:

i. La obligatoriedad está consagrada por la Constitución, junto al carácter secreto, en el artículo 77 numeral $2^{\circ}$. Cierto es que, durante un tramo importante de la historia, no fue sancionada la omisión, lo que significaba una forma de diluir el mandato constitucional.

ii. La falta de obligatoriedad puede tener relevancia en el resultado electoral porque dejarían de votar quienes se vieran imposibilitados o no estuvieran suficientemente motivados. Sería un pronunciamiento, en definitiva, de los entusiastas, militantes y movilizados, en que se estaría admitiendo y propiciando el desinterés y la abulia en torno al destino colectivo.

iii. Sobre las sugerencias de que se plebiscitara la aprobación en la misma hoja de vo- 
tación, eso está expresamente prohibido por el literal E del artículo 331 de la Constitución y podría violentar la voluntad del elector amen de excluir de la elección a los electores no ciudadanos del artículo 78 de la Carta.

En cuanto a la idea de una ley interpretativa, se han formulado objeciones afirmando que debe evitarse aplicar una postura que admita que por la vía de una "ley interpretativa" puede dejar de aplicarse las normas constitucionales. A este respecto, cabe señalar que la actividad interpretativa es constante, cualquier solución legal entraña una interpretación de la Constitución. Entiendo que, en todo caso, lo que cabe interpretar es la totalidad del sistema, que se integra, pero no se agota, con el artículo 44. Por otra parte, la denominación como "ley interpretativa", no es una fórmula mágica que transforme en constitucional lo que es inconstitucional.

Nosotros, manejamos la siguiente perspectiva, coincidiendo en cierta medida con los razonamientos expresados por los Dres. Ochs y Gutiérrez. Me permitiré citar algunas reflexiones que acogió el Semanario Búsqueda y alguna inédita que, también, manejamos oportunamente.

"Las normas se dictan para su aplicación a la realidad. A veces corren tras esta y otras, procuran modificarla, pero, en cualquier caso, la realidad no puede ser desconocida como dato esencial.

No se me escapa el riesgo que entraña sostener la relevancia de los hechos enfrentados a la consagración normativa. Una perspectiva desbordada, puede derivar en el desprecio por la norma, en las distintas expresiones de "realpolitik", en aquello de que "lo político está por encima de lo jurídico" y otras lindezas semejantes. Sin embargo, nadie puede concebir que la situación de hoy, tenga relación con ese tipo de designio subterráneo.

Reflexionando sobre el punto, nos encontramos con las consideraciones que realiza Reinaldo Vanossi ("Teoría Constitucional T. I, Buenos Aires, pág. 228), cuando postula, inspirado en la obra de Fritz Schreier, la existencia de una "norma de habilitación", que posibilita incluir en el derecho positivo, como válido, una disposición que, por contrariar la norma superior antecedente, sería en origen, nula.

Sostiene Vanossi: “¿Cómo puede darse la habilitación a ese nivel? Pues, sencillamente, por la falta de un recurso, por la imposibilidad de impugnación, por la carencia de un medio que quite validez a la norma de significación inferior que contradice a la superior. ... En definitiva, la habilitación equivale a la no impugnación, a la imposibilidad de impugnación".

Sobre la base de un razonamiento de esta índole, hemos asumido tradicionalmente como válidas las reformas constitucionales de 1934 y de 1942, derivadas y empleadas como medio de reinstitucionalización, tras sendos golpes de estado. Además, cabe señalar que nuestro sistema constitucional, en principio rígido, cede parcialmente esa rigidez cuando consagra que la eventual declaración de inconstitucionalidad sólo refiere al caso concreto 
y que sus efectos se limitan a los procedimientos objeto de pronunciamiento (art. 259), además de que ese pronunciamiento sólo procede cuando es posible argüir por parte del interesado, la existencia de un interés directo, personal y legítimo (art. 258).

Hay un concepto que merece ser considerado, el de "fuerza mayor" que, habitualmente, se aplica en el derecho contractual como justificativo ante la imposibilidad de cumplimiento. Henri Capitant (Vocabulario Jurídico, Buenos Aires, 1973), lo define como el "acontecimiento que no ha podido ser previsto ni impedido y que libera al deudor por imposibilidad de cumplir su obligación”. Manuel Ossorio (Diccionario de Ciencias Jurídicas, Políticas y Sociales, 1991) asimila el concepto al de "caso fortuito", aunque señala que algunos autores reservan esta última expresión a cuando la situación se vincula, mayoritariamente, a hechos de la naturaleza como, "por ejemplo, el desbordamiento de un río, los terremotos, las tempestades, las pestes, los incendios".

Y bien, en definitiva, el reconocimiento por el legislador de una situación de crisis imprevisible, sin antecedentes inmediatos, con el único propósito del amparo de la salud de nuestra población, que postergue en forma mínima el acto electoral, habilitando a que la Corte Electoral actúe en condiciones normales y evitando el riesgo de que alguien se contagie durante la espera, o la capacitación, o que evite, alternativamente, una abstención generalizada, no contradice la esencia de nuestro sistema democrático. Más bien, lo contrario"

"El reconocimiento, por el legislador, de la situación fáctica, pero expresando simultáneamente, la voluntad de realizar las elecciones en el menor tiempo posible, con el peso institucional y emblemático que supone la aprobación de una ley, constituye un acto valioso desde el punto de vista de la legitimación política.

¿Cuál es la razón para que el legislador tome intervención en el tema y se pronuncie en este caso especialísimo? Porque, el Parlamento es la expresión representativa en que se ubican las distintas corrientes que componen la opinión pública. No hay otro órgano en que se reflejen de modo más fiel, teniendo en cuenta el principio de representación proporcional integral que constituye una de las bases de nuestro sufragio. Es una expresión de consenso que legitima, al menos políticamente, a la solución de emergencia propiciada.

La mera participación en las elecciones por parte de la ciudadanía, conformaría una situación convalidante.

El empleo de reforma del artículo 331 literal D de la Constitución, que se ha sugerido como medio de convalidación reclama el voto aprobatorio "de la mayoría absoluta de los votos emitidos".

Creo que se hizo bien en desestimar esta posibilidad, a la que le reconozco que está excelentemente inspirada por magníficos exponentes de nuestra doctrina contemporánea, por las siguientes razones. 
La posición me recuerda a la hoy derogada remisión de ciertos delitos por ulterior casamiento del ofensor con la ofendida. El delito estaba cometido, y no había forma de eliminar el hecho histórico. Análogamente el plebiscito habría servido para redimir una suerte de pecado. Empero, en el caso que nos ocupa no hay violación de la Constitución, ni pecado a redimir.

Un problema insoluble sería, que no hubiera consentimiento de la ciudadanía en un eventual plebiscito, o aún que éste se expresara muy débilmente.

El artículo 331 literal D no dice expresamente que debe dársele a la ciudadanía la opción de votar por "No" - como sucede, en cambio, en el mecanismo de Convención Nacional Constituyente - o si, para que lo expresado tenga sentido, como el plebiscito coincidiría con la elección, hay que cotejar los votos por "Sí" con los votos emitidos, de modo de que el que no votase en forma aprobatoria, sería considerado un votante por "No". Korzeniak, en su Primer curso de Derecho Público, asume que debe dársele al ciudadano la posibilidad de votar por "No" y que es a esa disyuntiva a la que se refiere el constituyente (José Korzeniak, “1er Curso de Derecho Público. FCU 2001, pág. 112). Coincido con esta posición que fue, por otra parte, la seguida en el plebiscito de 1951, en el de agosto de 1994 y en el de 1996, en que se celebraron plebiscitos al amparo del artículo 331 literal D. Si la norma prevé una aprobación por mayoría absoluta de votos emitidos, implícitamente, se está imponiendo la necesidad de que se manifieste la opinión contraria. La previsión de un sufragio, supone la posibilidad de que haya, por lo menos, dos opciones (y que una gane y la otra pierda). Otra posibilidad no parece lógica. Si se pretende el pronunciamiento de la mayoría absoluta hay que usar un mecanismo, un ámbito, que habilite a que se conforme esa mayoría y se pronuncie superando a la minoría que sostiene una opinión contraria; tiene que haber un universo de votantes en el que esa mayoría se produzca Si el plebiscito fuera negativo, y esto no sería un imposible dado que la crisis puede generar reacciones neuróticas, antisistema, se sometería a la República a una situación insoluble. ¿Se equivoca Gerardo Caetano cuando afirma en El País de Madrid, el 26 de marzo, que "también el Uruguay viene procesando en su sociedad (como claramente lo indican las mediciones del Latinobarómetro y otras) un giro hacia visiones más críticas sobre el funcionamiento de la democracia y sobre los partidos políticos"?

Debe recordarse la suerte que corrió la "mini reforma", aprobada por el Poder Legislativo por más de $2 / 3$ de integrantes de cada Cámara, pero que, al ser plebiscitada el 28 de agosto de 1994, terminó cosechando únicamente el 28,5\% de los votos de los ciudadanos. El "sí" obtuvo 559.321 votos y el "no" 1.240.059.-

En cuanto a una eventual tacha de inconstitucionalidad de la ley. Es evidente que la decisión, justificada sin casi opiniones en contra, consagra una solución contraria a la disposición constitucional. 
Nuestra Constitución es rígida, sí, pero con importantes salvedades que derivan de los artículos 258 y 259 de la Constitución. No prospera un accionamiento de inconstitucionalidad si el planteo no se formula por quien no "se considere lesionado en su interés directo, personal y legítimo", circunstancia que es calificada por la Suprema Corte de Justicia, como resulta de su constante jurisprudencia. La Suprema Corte de Justicia rechaza los planteos de inconstitucionalidad cuando no son lesivos de ese interés y una hipótesis de ausencia de lesividad es que la ley que se impugna ya ha cumplido todos los efectos. En el caso, la elección no se habría hecho en el tiempo debido, y aparece un intento de restablecer la normalidad que no va en contra del sistema democrático ni de la soberanía nacional, sino que los reafirma.

Además, la declaración de inconstitucionalidad no tiene efectos generales, sino que se refiere "exclusivamente" para el caso concreto, entre las partes.

En otras palabras, entiendo que no es imaginable que la SCJ declare la inconstitucionalidad de una ley que tuviera el contenido de volver a la normalidad, superados en medida suficiente los efectos de la pandemia. 